\title{
Oral immunisation as a strategy for enhancing corneal allograft survival
}

\author{
Ding Ma, Jessamee Mellon, Jerry Y Niederkorn
}

\begin{abstract}
Aims-To determine optimal conditions for enhancing corneal allograft survival through oral administration of donor specific corneal cells.

Methods-A mouse model of penetrating keratoplasty was used to evaluate the efficacy and optimal conditions for preventing immunological rejection of corneal allografts. C3H corneal grafts were transplanted orthotopically to $\mathrm{CB} 6 \mathrm{~F} 1$ recipients and represented mismatches at the entire major histocompatibility complex (MHC) and multiple minor histocompatibility loci. Tissue cultured $\mathrm{C} 3 \mathrm{H}$ corneal epithelial and endothelial cells were administered orally to CB6F1 mice before or shortly after the application of orthotopic C3H corneal allografts. Cultured C3H corneal cells were conjugated with the non-toxic $B$ subunit of cholera toxin as a means of preferentially inducing oral tolerance.
\end{abstract}

Results-Ten oral doses of donor cells administered before keratoplasty reduced the incidence of corneal graft rejection from $100 \%$ in untreated hosts to $54 \%$ in orally tolerised mice. Conjugation of cholera toxin to corneal cells significantly enhanced the efficacy of oral tolerance such that only $9 \%$ of the mice fed 10 doses of cholera toxin conjugated cells rejected their corneal grafts. Even a single oral inoculation of corneal cells conjugated to cholera toxin was able to reduce corneal graft rejection by $36 \%$.

Conclusions-Oral administration of donor specific cells greatly enhances corneal graft survival. Use of cholera toxin adjuvant markedly enhances the efficacy of oral tolerance such that even a single oral dose of donor cells significantly reduces the incidence of rejection. The results support the clinical feasibility of this novel strategy for preventing immunological rejection of corneal transplants. (Br f Ophthalmol 1997;81:778-784)

Corneal transplantation is the most common and arguably the most successful form of solid tissue transplantation. In uncomplicated cases, the rejection rate for keratoplasty is approximately $10 \%$ in the first year but rises to $21 \%$ by the third year after surgery. ${ }^{12}$ However, in spite of this success, a significant number of corneal grafts fail because of immunological rejection. Indeed, immunological rejection remains the leading cause of corneal allograft failure. ${ }^{1}$ Moreover, the risk of rejection rises sharply in patients who have rejected a previous corneal graft. ${ }^{1-3}$ Although corticosteroids and cyclosporin A have greatly reduced the rejection rate of corneal allografts, their prolonged use and high dosage can produce deleterious side effects including glaucoma, cataract formation, nephrotoxicity, hypertension, and hepatotoxicity. ${ }^{45}$ Less toxic alternative methods of immunosuppression are still needed for corneal transplantation.

It was recognised early in this century that oral antigen administration was an effective method of desensitising hosts previously immunised with allergens. ${ }^{6}$ Subsequent studies demonstrated the therapeutic value of oral desensitisation as a means of ameliorating a variety of experimental autoimmune diseases including experimental autoimmune encephalomyelitis, ${ }^{7}$ experimental autoimmune uveitis, ${ }^{8}$ arthritis, ${ }^{9}$ and type I diabetes. ${ }^{10}$ Oral immunisation has also produced encouraging results in randomised, double blind clinical trials involving multiple sclerosis and rheumatoid arthritis patients. ${ }^{11} 12$ Although the term 'oral tolerance' has been used widely to describe the down regulation of immune responses to a variety of antigens, ${ }^{7-12}$ it is unclear if the unresponsiveness is permanent.

Oral immunisation has recently been shown to be an effective strategy for reducing corneal allograft rejection in mouse ${ }^{13}$ and rat $^{14}$ models of penetrating keratoplasty. Oral administration of donor specific corneal cells reduced the incidence of rejection of corneal grafts mismatched at the entire major histocompatibility complex (MHC) and multiple minor histocompatibility loci from $100 \%$ to $55 \%$ in naive hosts. ${ }^{13}$ The orally induced enhancement of corneal allograft survival was restricted to donor alloantigens and correlated with a profound suppression of donor specific cytotoxic $\mathrm{T}$ lymphocyte and delayed type hypersensitivity responses. ${ }^{13}$ Based on these promising preliminary results, we evaluated several 
strategies for optimising the clinical feasibility of oral tolerance as a method for preventing corneal allograft rejection. We also examined factors which might impede the induction of oral tolerance and jeopardise corneal allograft survival.

\section{Materials and methods}

ANIMALS

Female C3H/Hej $\left(\mathrm{H}-2^{\mathrm{k}}\right)$ and CB6F1 $\left(\mathrm{H}-2^{\mathrm{b} / \mathrm{d}}\right)$ mice were reared in the Department of Microbiology Animal Colony at the University of Texas Southwestern Medical Center (Dallas, TX, USA) and were used between the ages of 2 and 8 months.

\section{CORNEAL CELL CULTURES}

Tissue cultured murine corneal epithelial and endothelial cells were used as alloantigens for the induction of oral tolerance. Cell cultures were established from freshly dissected corneal explants ${ }^{15}$ and propagated in minimal essential medium (MEM) supplemented with $10 \%$ fetal calf serum. After the primary cultures were established, these cells were immortalised with human papilloma virus genes E6 and E7 using the disabled recombinant retroviral vector pLXSN16E6/E7. ${ }^{17}$ These cells proliferate indefinitely while maintaining their original morphological characteristics. Furthermore, the cells express the same histocompatibility antigens as their non-transformed counterparts. ${ }^{13}$

ADHERENT SPLEEN CELL PREPARATION

Spleen cell suspensions were enriched for $\mathrm{Ia}^{+}$ dendritic cells (DC) as previously described. ${ }^{18}$ Briefly, spleen cells were pressed through a fine stainless steel sieve. Erythrocytes were removed with a 4 minute incubation in ACT (ammonium chloride, $\mathrm{KH}_{2} \mathrm{O}_{4}$ ) solution at $37^{\circ} \mathrm{C}$, followed by washing three times in Hank's balanced salt solution (HBSS). Adherent cells were separated by incubating cell suspensions $\left(5 \times 10^{6}\right.$ cells $\left./ \mathrm{ml}\right)$ on plastic tissue culture dishes (Falcon 3803, Becton Dickinson, Oxnard, CA, USA) at $37^{\circ} \mathrm{C}$ in $5 \%$ carbon dioxide for 90 minutes. Non-adherent cells were washed gently with HBSS and adherent cells were collected by gentle scraping with a Teflon policeman and rinsing with HBSS. Adherent spleen cell suspensions prepared in this manner contain $>70 \% \mathrm{Ia}^{+}$cells. ${ }^{18}$

ORAL TOLERANCE INDUCTION

Cultured murine corneal cells and splenic adherent cells were used for inducing oral tolerance. In some experiments, the non-toxic B subunit of cholera toxin was conjugated to $\mathrm{C} 3 \mathrm{H}$ corneal epithelial and endothelial cells before oral administration. Cholera toxin B subunit (CTB; Sigma Chemical Co, St Louis, MO, USA) was conjugated to corneal cells by incubating $100 \mu \mathrm{g}$ of CTB with a cell suspension containing $5 \times 10^{6}$ corneal epithelial cells and $5 \times 10^{6}$ corneal endothelial cells in $1.0 \mathrm{ml}$ of HBSS. The cell suspension was incubated for 2 hours at $37^{\circ} \mathrm{C}$ with frequent shaking followed by three washes in HBSS. The efficiency of the CTB conjugation procedure was confirmed by incubating corneal cell suspensions with $100 \mu \mathrm{g}$ of FITC labelled CTB (Sigma) using the same protocol and viewing the conjugated cells by fluorescent microscopy.

For each immunisation, either $2 \times 10^{6}$ splenic DC or a mixture of $1 \times 10^{6}$ epithelial cells plus $1 \times 10^{6}$ endothelial cells was administered directly into the stomach using a gavage tube. In some experiments human recombinant IL-2 (National Cancer Institute, Biologic Response Modifiers Program; Hoffmann-La Roche, Inc, Nutley, NJ, USA) was administered intraperitoneally for 10 days at a dose of 1000 units/injection.

\section{SPLENECTOMY}

Mice were deeply anaesthetised with $0.66 \mathrm{mg}$ of ketamine hydrochloride (Vetalar; Parke, Davis, and Co, Detroit, MI, USA) given intramuscularly. An incision was made on the shaved abdomen and the spleen was exposed. The spleen was exteriorised and excised. Haemorrhage was arrested by tamponade and the wound closed with sterile stainless steel wound clips. Wound clips were removed 7-10 days later.

ORTHOTOPIC CORNEAL TRANSPLANTATION Full thickness penetrating $\mathrm{C} 3 \mathrm{H}\left(\mathrm{H}-2^{k}\right)$ corneal grafts $(2.5 \mathrm{~mm}$ diameter $)$ were transplanted orthotopically onto anaesthetised CB6F1 (H$2^{\mathrm{b} / \mathrm{d}}$ ) mice using a procedure previously described by She et al ${ }^{19}$ and modified by $\mathrm{He} e t$ $a l .{ }^{20}$ Mice were anaesthetised with an intraperitoneal injection of sodium pentobarbitone (1-2 mg per mouse; Abbott Laboratories, Chicago, IL, USA). Proxymetacaine (proparacaine) was used as a topical anaesthetic (Alcon Laboratories, Fort Worth, TX, USA). Both the donor graft and the recipient graft bed were scored with $2.5 \mathrm{~mm}$ and $2.0 \mathrm{~mm}$ diameter trephines, respectively (Storz Instruments, St Louis, MO, USA) before removal of the corneal button using vannas scissors (Storz). The donor graft was sewn into place using 12 interrupted 11-0 nylon sutures and a $50 \mu \mathrm{m}$ diameter needle (2881G Ethicon, Somerville, NJ, USA). Sutures were removed 7 days later. Topical antibiotic (AK-POLY-BAC; bacitracin zinc and polymyxin B sulphate; Akorn Inc, Abita Springs, LA, USA) was applied immediately after surgery and after suture removal. No immunosuppressive drugs were used.

CLINICAL OBSERVATIONS

Grafted eyes were examined with a slit-lamp biomicroscope at least twice a week throughout the entire study period. Graft opacity, oedema, and neovascularisation were scored as minimal, moderate, or severe, as previously described. ${ }^{21}$ If all three factors became moderate or severe more than 7 days after transplantation, the graft was recorded as rejected on that day. Any host that developed complications such as cataract, anterior chamber loss, iris synechiae, or infection, was excluded from the study. Mean survival time was calculated for each group and used for expressing the results as 'percentage graft survival'. Median 


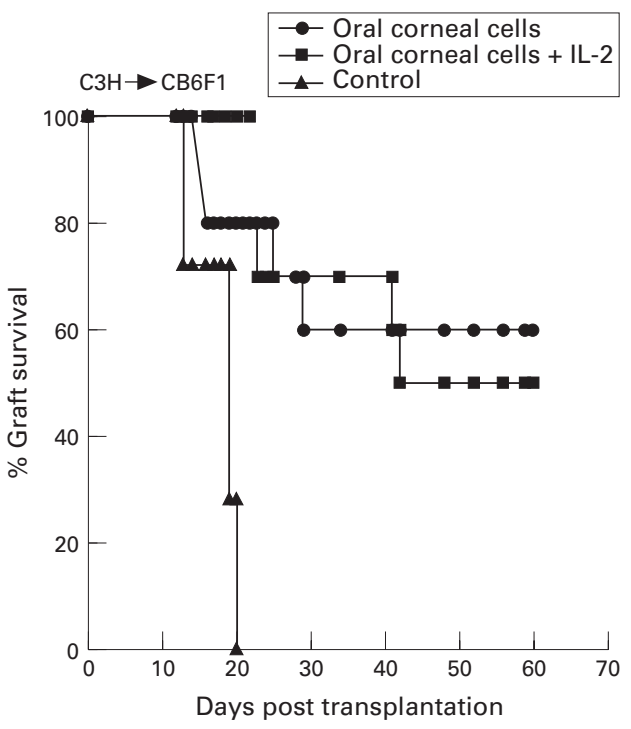

Figure 1 Effect of IL-2 on the induction of oral tolerance and corneal allograft survival. CB6F1 mice received 10 daily inocula of $\mathrm{C} 3 \mathrm{H}$ corneal cells. One group of orally treated mice also received 10 daily intraperitoneal injections of human rIL-2 (1000 units/day). Mice received orthotopic C3H corneal allografts 1 day after the final oral inoculum. $N=10$ in each group. Corneal cells $+I L-2$ group and corneal cells group without IL-2 were insignificantly different $(p>0.05)$; both groups were significantly different from untreated controls $(p=0.003)$.

graft survival times were also calculated and used to determine the statistical significance by the Mann-Whitney test. Differences in the incidence of rejection were evaluated by $\chi^{2}$ analysis.

\section{Results}

The goal of this study was to evaluate the efficacy of three strategies which we predicted would enhance oral tolerance and promote corneal allograft survival. We also examined the effects of two factors which were likely to impair the successful induction of oral tolerance.

EFFECT OF EXOGENOUS IL-2 ON ORAL TOLERANCE A previous report demonstrated that administration of as few as three intraperitoneal injections of 1000 units of IL-2 significantly enhanced orally induced tolerance to interphotoreceptor retinoid binding protein (IRBP). ${ }^{22}$ Accordingly, experiments were designed to test the effect of IL-2 on the induction of oral tolerance to alloantigens and corneal graft survival. $\mathrm{CB} 6 \mathrm{~F} 1$ mice received 10 daily oral doses of $2 \times$ $10^{6} \mathrm{C} 3 \mathrm{H}$ corneal epithelial and endothelial cells. Another group of $\mathrm{CB} 6 \mathrm{~F} 1$ mice received the same oral antigen preparation and daily intraperitoneal injections of 1000 units of human rIL-2. Orally tolerised mice, as well as untreated control mice, were grafted 24 hours after the 10th oral inoculum. As expected, $100 \%$ of the $\mathrm{C} 3 \mathrm{H}$ corneal grafts were rejected by the untreated $\mathrm{CB} 6 \mathrm{~F} 1$ hosts with a mean survival time (MST) of 18.0 (SD 2.7) days. Oral administration of corneal cells produced a significant enhancement of corneal graft survival. Only $40 \%$ of the orally tolerised hosts rejected their grafts (Fig 1). Unlike the previous results with IRBP, administration of

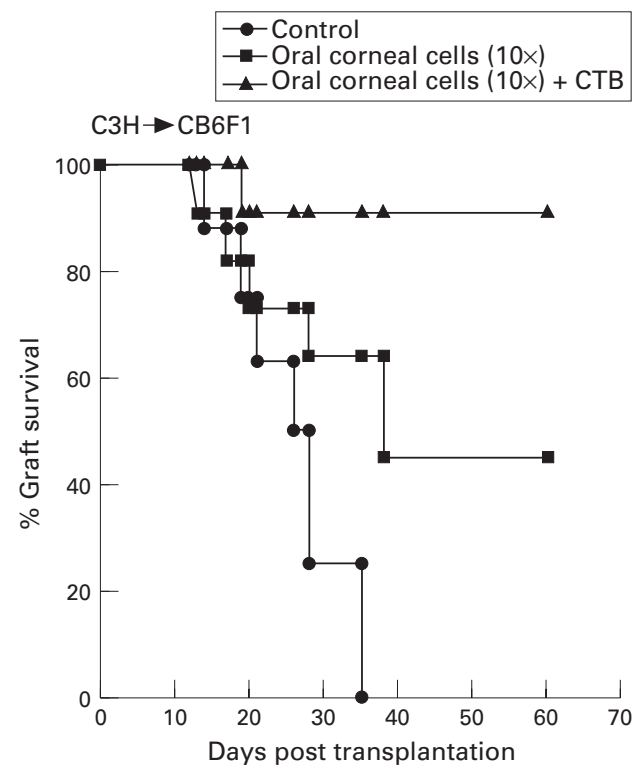

Figure 2 Enhancement of oral tolerance using cholera toxin. CB6F1 mice received 10 daily inocula of $C 3 \mathrm{H}$ corneal cells conjugated with cholera toxin B subunit $(C T B)$ or non-conjugated $C 3 H$ corneal cells. All mice were challenged with orthotopic $C 3 H$ corneal grafts 1 day after the final oral inoculum. $N=11$, corneal cells; $n=11$, corneal cells conjugated with $C T B ; n=8$, untreated control; $p=0.02$ for corneal cells $+C T B$ group compared with control and corneal cells alone groups.

IL-2 during the period of alloantigen feeding did not augment oral tolerance. Both the incidence and tempo of corneal graft rejection in the IL-2 supplemented mice were insignificantly different from mice fed corneal alloantigens but not supplemented with IL-2.

AUGMENTATION OF ORAL TOLERANCE WITH CHOLERA TOXIN

Conjugation of CTB to soluble antigens has a profound effect on the induction of oral tolerance. Orally administered CTB conjugated antigens are effective at suppressing delayed type hypersensitivity responses at antigen doses 15 to 500 times lower than non-conjugated antigens given by the oral route. ${ }^{23}$ The possibility that a similar effect might occur with corneal alloantigens was examined. Corneal cells were conjugated with CTB-FITC to confirm the efficiency of CTB conjugation. Examination of the treated cells revealed that CTB-FITC bound extensively to the corneal cells, with over $95 \%$ of the cells displaying positive fluorescence (data not shown). Therefore, subsequent experiments utilised nonfluoresceinated CTB for conjugating corneal cells. Panels of mice were fed 10 consecutive doses of either non-conjugated corneal cells or corneal cells conjugated with CTB. Orthotopic $\mathrm{C} 3 \mathrm{H}$ grafts were applied 1 day after the 10th oral antigen inoculum. As in the previous experiments, oral administration of 10 doses of corneal cells resulted in a steep reduction in corneal graft rejection. Conjugation of CTB to the corneal cells significantly enhanced oral tolerance. Rejection occurred in only one of the 11 mice fed CTB conjugated corneal cells (Fig 2). The remarkable augmentation produced by CTB suggested that it might be pos- 


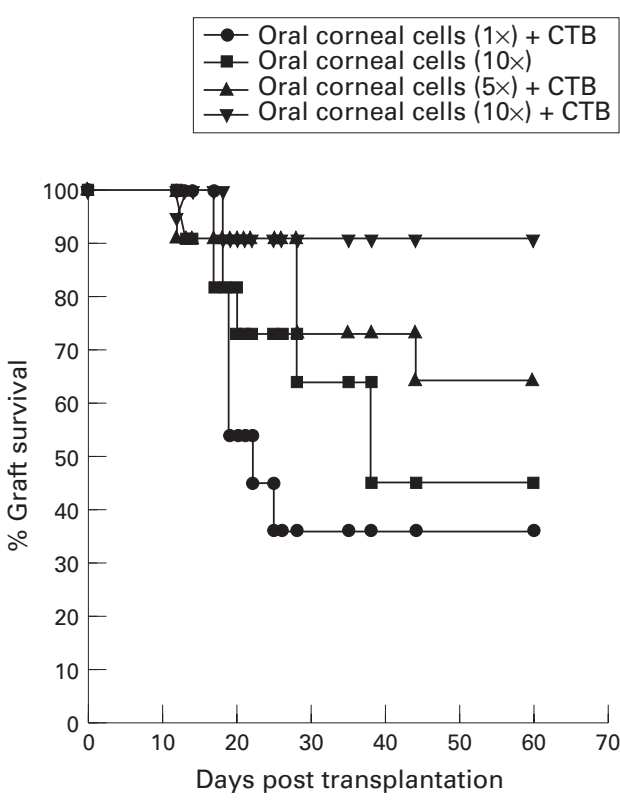

Figure 3 Dose response characteristics of cholera toxin enhancement of oral tolerance. CB6F1 mice received either 1,5 , or 10 oral inocula of $C T B$ conjugated $C 3 H$ corneal cells. All mice were challenged with orthotopic $C 3 H$ corneal grafts 1 day after the final oral inoculum. $N=11$ for all groups. $p>0.05$, corneal cells $(1 \times)+C T B$ compared with corneal cells $(10 \times)$ without $C T B$.

sible to reduce the number of oral doses of corneal cells needed to enhance graft survival. Accordingly, mice were given either five daily oral inocula or a single oral inoculum of cornea cells 24 hours before grafting. The results indicated that even a single oral inoculum of CTB conjugated corneal cells prevented corneal graft rejection in $36 \%$ of the mice and was as effective as 10 doses of non-conjugated corneal cells (Fig 3). Although five oral doses of corneal cells prevented graft rejection in $64 \%$ of the hosts, optimal graft enhancement was achieved with 10 doses of CTB conjugated corneal cells.

TIMING OF ORAL ANTIGEN ADMINISTRATION AND GRAFT ENHANCEMENT

From a clinical perspective, it is important to determine the optimal timing for orally administering alloantigens. This is particularly relevant since the limited shelf life of corneal buttons might prevent the full implementation of the optimal oral tolerance protocol before keratoplasty. Therefore, it was of interest to determine if oral antigen administration could be initiated at the time of corneal transplantation or shortly thereafter and still have a beneficial effect on graft survival. For these experiments, 10 doses of either CTB conjugated or non-conjugated corneal cells were administered beginning either on the day of keratoplasty or 7 days later. The results demonstrate that initiating antigen feeding on the day of keratoplasty was highly effective in preventing corneal graft rejection; only three of the 16 mice rejected their corneal grafts (Fig 4). Although delaying oral antigen administration until 7 days after keratoplasty reduced the efficacy of oral tolerance, it none the less

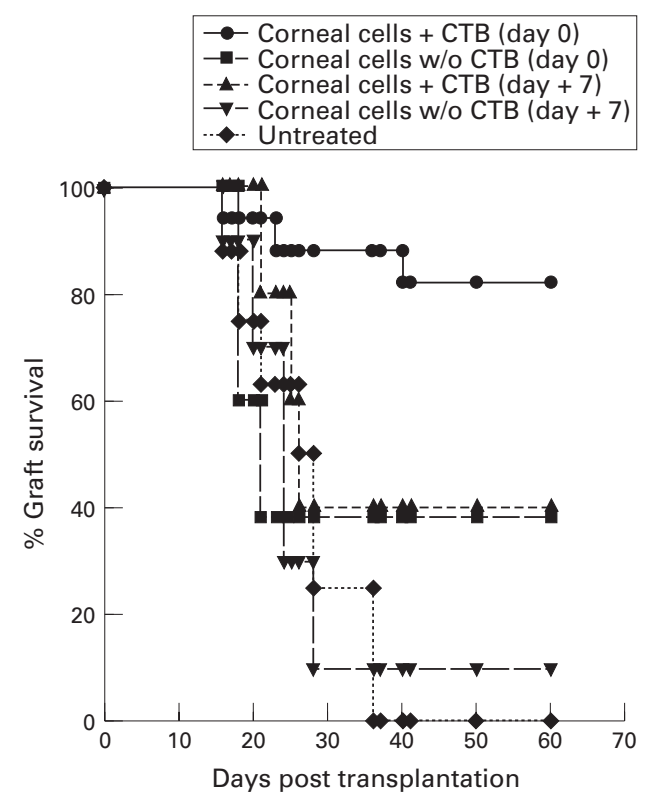

Figure 4 Effect of delayed induction of oral tolerance on corneal allograft survival. CB6F1 mice received 10 oral inocula of non-conjugated or CTB conjugated $C 3 H$ corneal cells beginning on the day of orthotopic corneal transplantation (day 0) or 7 days later (day +7). There were 10 animals in each group except the corneal cells + $C T B$ (day 0) group which had 16 mice. $p=0.002$, corneal cells $+C T B($ day 0$)$ compared with untreated control group; $p=0.002$, corneal cells $+C T B($ day +7$)$ compared with untreated control group.

reduced graft rejection by $40 \%$ compared with the untreated control group.

SPLENIC REQUIREMENT FOR ORAL TOLERANCE In the course of evaluating therapeutic strategies for enhancing oral tolerance, it is important to consider factors which might impair the induction of oral tolerance and thereby jeopardise corneal allograft survival.

It has been shown previously that successful induction of oral tolerance to retinal $\mathrm{S}$ antigen requires the presence of an intact spleen. ${ }^{24}$ Although it might seem obvious that an intact spleen would also be necessary for the induction of tolerance to corneal alloantigens, the results from the IL-2 experiments described above suggest that corneal alloantigens and retinal autoantigens are processed by different pathways following oral administration. Accordingly, the effect of an intact spleen on the induction of oral tolerance to corneal alloantigens was examined. Splenectomised and eusplenic $\mathrm{CB} 6 \mathrm{~F} 1$ mice were given 10 consecutive oral doses of $\mathrm{C} 3 \mathrm{H}$ corneal cells before receiving penetrating keratoplasties. As in previous experiments, eusplenic mice given 10 oral doses of $\mathrm{C} 3 \mathrm{H}$ corneal cells experienced a significantly lower incidence of graft rejection (Fig 5). An intact spleen was clearly necessary for enhancement of corneal allograft survival as splenectomised mice fed corneal cells rejected $100 \%$ of their grafts in a tempo that was indistinguishable from untreated eusplenic controls. 


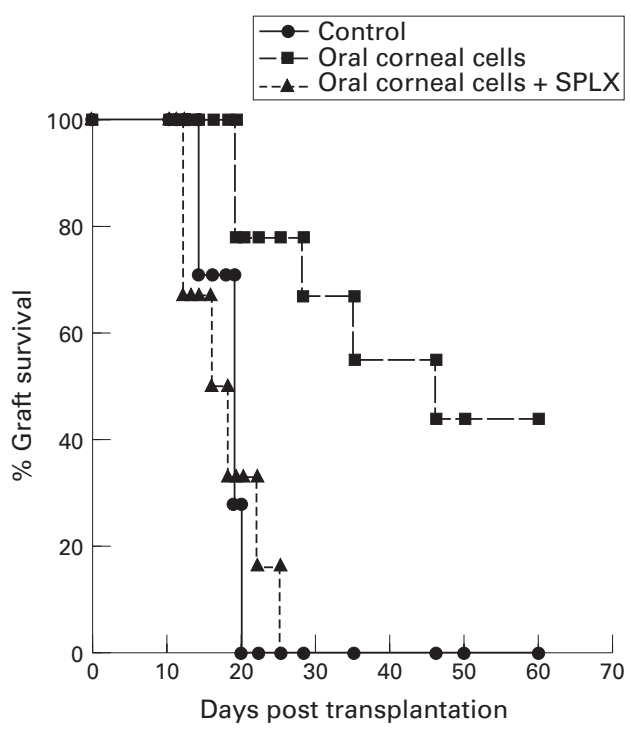

Figure 5 An intact spleen is needed for the induction of oral tolerance and enhancement of corneal graft survival. CB6F1 mice received 10 daily inocula of $C 3 \mathrm{H}$ corneal cells and were grafted 1 day after the final oral inoculum. $N=$ 6 , splenectomy (SPLX) group; $n=9$, oral corneal cell group; $n=7$, untreated control group. Difference in survival times between splenectomy group and oral corneal cell group was significant $(p=0.004)$.

EFFECT OF DONOR ANTIGEN PRESENTING CELLS ON THE INDUCTION OF ORAL TOLERANCE AND CORNEAL GRAFT ENHANCEMENT

Donor specific antigen presenting dendritic cells (DC) are potent inducers of alloimmune responses and graft rejection. ${ }^{25}$ As few as 10 dendritic Langerhans cells are capable of inducing alloimmunity that results in the accelerated rejection of subsequent skin allografts. ${ }^{26}$ Therefore, the next experiments tested the hypothesis that not all alloantigen bearing cells are capable of inducing oral tolerance and that oral administration of potent donor specific antigen presenting DC might induce alloimmune responses that culminate in the accelerated rejection of subsequent corneal allografts. The results, however, indicated that this was not the case. Oral administration of splenic DC produced significant enhancement of corneal graft survival (Fig 6). However, administration of exogenous IL-2 ablated the beneficial effects of orally administered DC and resulted in the rejection of $87 \%$ of the grafts. Although the incidence of corneal graft rejection was slightly higher in hosts fed splenic DC (that is, $63 \%$ rejection) compared with hosts fed corneal cells (that is, $40 \%$ ), graft survival in both groups was significantly greater than untreated controls (Figs 1 and 6).

\section{Discussion}

Although corneal grafts have an excellent success rate compared with other categories of transplants, $10 \%-20 \%$ will fail as a result of immunological rejection. ${ }^{12}$ The toxic side effects of cyclosporin A and other potent systemic immunosuppressive agents have stimulated interest in non-pharmacological alternatives for preventing graft rejection. The present study evaluated the potential of oral administration of alloantigens as a strategy for

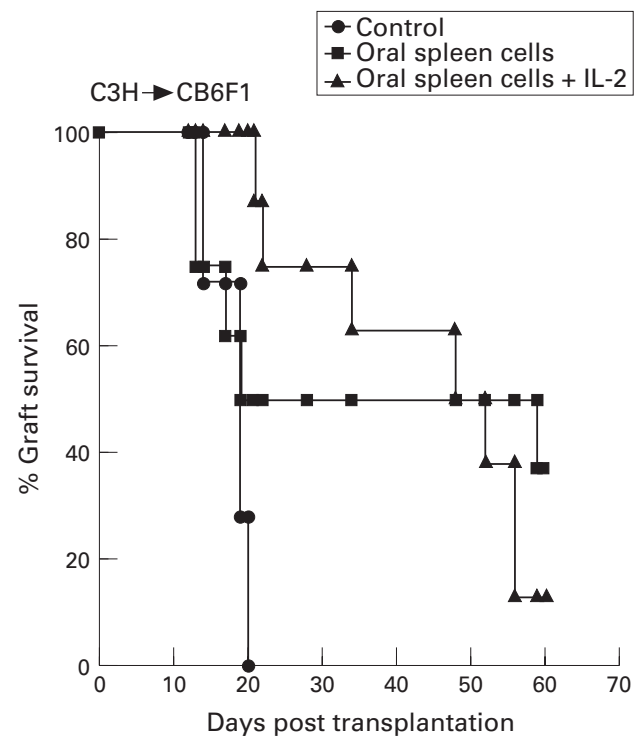

Figure 6 Induction of oral tolerance with splenic dendritic cells. CB6F1 mice received 10 daily inocula of $C 3 \mathrm{H}$ adherent spleen cells. One group of orally treated mice also received 10 daily intraperitoneal injections of human rIL-2 (1000 units/day). Mice received orthotopic $C 3 \mathrm{H}$ corneal allografts 1 day after the final oral inoculum. $N=8$, adherent spleen cells $+I L-2 ; n=8$, adherent spleen cells alone; and $n=10$, controls. $p=0.24$ spleen cell group compared with spleen cells $+I L-2 ; p=0.03$, spleen cells without IL-2 group compared with untreated control; $p>0.05$, spleen cells $+I L-2$ compared with untreated control group.

preventing corneal graft rejection. The experiments were designed to identify optimal conditions for inducing oral tolerance and augmenting corneal graft survival. The studies also evaluated potential risk factors which might prevent the successful induction of oral tolerance and jeopardise corneal graft survival.

Administration of exogenous IL-2 has been shown to greatly augment oral tolerance induced against IRBP in rodents. ${ }^{22}$ However, intraperitoneal injections of IL-2 throughout the entire period of oral antigen administration failed to significantly reduce the incidence of rejection or to prolong the survival of corneal allografts beyond that found in animals fed corneal cells alone. It is unlikely that administration of larger quantities of IL-2 would have enhanced oral tolerance to corneal alloantigens since a single injection of 1000 units of IL-2 was as effective as three separate injections of 30000 units of IL-2 (total of 90000 units) in inducing oral tolerance to IRBP. ${ }^{22}$ Thus, it appears that the induction of oral tolerance to corneal alloantigens is not augmented by exogenous IL-2.

The presence of an intact spleen is crucial for the induction and expression of oral tolerance to retinal $S$ antigen in rodents. ${ }^{24}$ The present results indicate that the same principle applies to oral tolerance to corneal alloantigens and enhancement of corneal allograft survival. Splenectomised mice failed to respond to oral alloantigen induced tolerance and behaved no differently from untreated controls. This suggests that crucial immunoregulatory processes occur in the spleen of orally tolerised mice. This conclusion is further supported by previous findings which demonstrated that 
enhancement of corneal graft survival could be adoptively transferred to naive recipients using spleen cells from orally tolerised donors. ${ }^{13}$ The nature and identity of the spleen cells involved in oral induced enhancement of corneal allograft survival are currently under investigation in our laboratory.

Donor specific DC are potent instigators of alloimmunity and greatly increase the immunogenicity of allografts. ${ }^{25} 27$ However, spleen cell suspensions intentionally prepared to contain large numbers of DC, induced oral tolerance and produced a significant enhancement of corneal allograft survival. Although the spleen cell suspensions also contained macrophages, the protocol produces spleen cell suspensions highly enriched with $\mathrm{DC} .{ }^{28} \mathrm{On}$ a per cell basis, DCs are the most potent cell for stimulating alloimmune responses. ${ }^{25}{ }^{27}$ As few as 10 dendritic Langerhans cells are capable of inducing alloimmunity and skin allograft rejection. ${ }^{26}$ Thus, parenteral administration of $2 \times 10^{6}$ spleen cells containing $70 \% \mathrm{Ia}^{+}$cells induces potent alloimmunity, yet when given orally results in enhanced allograft survival. These results combined with previous findings which demonstrated that keratinocytes were as effective as corneal cells in promoting corneal graft survival, ${ }^{13}$ suggest that perhaps a wide variety of cells, even cells considered to be highly immunogenic, can be used to enhance corneal graft acceptance.

Perhaps the most important finding from this investigation is the remarkable adjuvant effect of CTB. A single oral dose of CTB conjugated corneal cells reduced corneal graft rejection by $36 \%$. Moreover, 10 doses of CTB conjugated corneal cells, given before keratoplasty, prevented rejection in all but one mouse. Oral administration of non-conjugated corneal cells reduced the risk of rejection significantly, but only if given before keratoplasty. However, oral administration of CTB conjugated cells could be delayed up to 7 days after keratoplasty and still produce significant enhancement of graft survival.

The mechanism whereby CTB enhances oral tolerance is poorly understood. Native cholera toxin is a well recognised adjuvant for activating the mucosal immune system and inducing the preferential secretion of secretory IgA immunoglobulin. ${ }^{29}$ The physicochemical association between cholera toxin and orally administered antigens is crucial in determining the nature of the systemic immune response. When cholera toxin is administered orally with an unrelated antigen it prevents the induction of oral tolerance. ${ }^{30}$ Even minute quantities of contamination with free cholera toxin can abrogate the tolerogenic properties of orally administered CTB conjugated antigens. ${ }^{30}$ Moreover, CTB must be covalently conjugated to the oral antigen in order for tolerance to be effectively induced; oral administration of nonconjugated CTB and antigen fails to induce immunological tolerance. ${ }^{23}$ In spite of these fastidious requirements, CTB is a highly effective adjuvant for facilitating immunological tolerance to histocompatibility antigens.
In summary, these findings support the feasibility of oral tolerance as a means of reducing corneal allograft rejection without resorting to potentially toxic immunosuppressive drugs. Moreover, the down regulation of alloimmunity and graft enhancement is antigen specific as immune responses to third party alloantigens are intact. ${ }^{13}$ Thus, oral administration of allogeneic cells should not compromise the host's capacity to respond to unrelated antigens such as pathogens. The implementation of CTB as an adjuvant markedly enhances the efficacy of oral tolerance and permits the use of a less intensive and restricted tolerising protocol. The remarkable capacity of CTB conjugated cells to prevent rejection in an otherwise high risk setting suggests that oral administration of alloantigenic cells warrants serious consideration for use in high risk keratoplasty patients.

This work was supported in part by NIH grant EY07641 and an unrestricted grant from Research to Prevent Blindness, Inc, New York.

1 The Collaborative Corneal Transplantation Studies Research Group. The collaborative corneal transplantation studies (CCTS). Effectiveness of histocompatibility matching in high-risk corneal transplantation. Arch Ophthalmol 1992;110:1392-403.

2 Williams KA, Roder D, Muehlberg SM, Coster DJ. Factors predictive of corneal graft survival. Ophthalmology 1992;99: predictive $403-14$.

3 Lindstrom RL. Advances in corneal transplantation. $N$ Engl f Med 1986;315:57-9.

4 Belin MW, Bouchard CS, Phillips TM. Update on topical cyclosporin A: background, immunology and pharmacology. Cornea 1990;9:184-95.

5 Dupon E, Wybran J, Tonssaint C. Glucocorticosteroids and organ transplantation. Transplantation 1984;37:331-5

6 Mowat AM. The regulation of immune responses to dietary protein antigens. Immunol Today 1987;8:93-8.

7 Higgins PJ, Weiner HL. Suppression of experimental autoimmune encephalomyelitis by oral administration of myelin basic protein and its fragments. F Immunol 1988;140:440-5.

8 Nussenblatt RB, Caspi RR, Mahdi R, Chan CC, Roberge F, Lider $\mathrm{O}$, et al. Inhibition of S-antigen induced experimental autoimmune uveoretinitis by oral induction of tolerance with S-antigen. F Immunol 1989;144:1689-95.

9 Zhang Z, Lee C, Weiner H. Suppression of adjuvant arthritis by oral administration of type II collagen. F Immunol 1990;145:2489-93.

10 Zhang Z, Davidson L, Elisenbarth G, Weiner H. Suppression of diabetes in nonobese diabetic mice by oral adminission of diabetes in nonobese diabetic mice by oral administration of por $10252-6$.

11 Weiner HL, Mackin GA, Matsui M, Orav EJ, Khoury SJ, Dawson DM, et al. Double-blind pilot trial of oral tolerization with myelin antigens in multiple sclerosis. Science 1993;259:1321-4.

12 Trentham DE, Dynesius-Trentham RA, Orav EJ, Combitchi D, Lorenzo C, Sewell KL, et al. Effects of oral administration of type II collagen on rheumatoid arthritis. Science 1993;261:1727-30.

13 He Y-G, Mellon J, Niederkorn JY. The effect of oral immunization on corneal allograft survival. Transplantation 1996; 61:920-6.

14 Feder JM, Antonyhsamy MA, Moticka EJ. Oral administration of alloantigens enhances corneal allograft survival. Invest Ophthalmol Vis Sci (Suppl) 1995;36:S1010.

15 He YG, McCulley JP. Growing human corneal epithelium on collagen shield and subsequent transfer to denuded coron collagen shield and subsequent transfer

16 Yue BYJT, Sugar J, Gilboy JE, Elvart JL. Growth of human corneal endothelial cells in culture. Invest Ophthalmol Vis Sci 1989;30:248-53.

17 Wilson SE, Weng J, Blair S, He Y-G, Lloyd S. Expression of E6/E7 or SV40 large T antigen-coding oncogenes in human corneal endothelial cells indicates regulated highproliferative capacity. Invest Ophthalmol Vis Sci 1995;36: $32-40$.

18 Benson JL, Niederkorn JY. The presence of donor-derived class II-positive cells abolishes immune privilege in the anterior chamber of the eye. Transplantation 1991;51:8348.

19 She SC, Steahly LP, Moticka EJ. A method for performing full-thickness, orthotopic, penetrating keratoplasty in the mouse. Ophthalmic Surg 1990;21:781-5.

20 He YG, Ross J, Niederkorn JY. Promotion of murine orthotopic corneal allograft survival by systemic administration of anti CD4 monoclonal antibody. Invest Ophthalmol Vis Sci 1991;32:2723-8. 
21 Holland EJ, Chan C-C, Wetzig RP, Palestine AG, Nussenblatt RB. Clinical and immunohistologic studies of corneal rejection in the rat penetrating keratopasty model. Cornea 1991;10:374-80.

22 Rizzo LV, Miller-Rivero NE, Chan C-C, Wiggert B, Nussenblatt RB, Caspi RR. Interleukin-2 treatment potentiates induction of oral tolerance in a murine model of autoimmunity. F Clin Invest 1994;94:1668-72.

23 Sun J-B, Holmgren J, Czerkinsky C. Cholera toxin B subunit: an efficient transmucosal carrier-delivery system for induction of peripheral immunological tolerance. Proc Natl Acad Sci (USA) 1994;91:10795-9.

24 Suh EDW, Vistica BP, Chan C-C, Raber JM, Gery I, Nussenblatt RB. Splenectomy abrogates the induction of oral tolerance in experimental autoimmune uveoretinitis. Curr Eye Res 1993;12:833-9.
25 Steinman $\mathrm{R}$. The dendritic cell system and its role in immunogenicity. Annu Rev Immunol 1991;9:271-96.

26 McKinney EC, Streilein JW. On the extraordinary capacity of allogeneic epidermal Langerhans cells to prime cytotoxic $\mathrm{T}$ cells in vivo. F Immunol 1989;143:1560-4.

27 Austyn JM, Steinman RM. The passenger leukocyte-a fresh look. Transplant Rev 1988;2:139-76.

28 Klinkert WEF, Labadie JH, Bowers WE. Accessory and timulating properties of dendritic cells and macrophages isolated from various rat tissues. F Exp Med 1982;156:1-19.

29 McKenzie SJ, Halsey JF. Cholera toxin B subunit as a carrier protein to stimulate a mucosal immune response. $\mathcal{f}$ Immunol 1984;133:1818-24.

30 Elson CO, Ealding W. Generalized systemic and mucosal immunity in mice after mucosal stimulation with cholera toxin. F Immunol 1984;132:2736-41. 